\title{
Pro-vegetarian food patterns and cardiometabolic risk in the PREDIMED-Plus study: a cross-sectional baseline analysis
}

\author{
Alejandro Oncina-Cánovas ${ }^{1,2,3} \cdot$ Jesús Vioque ${ }^{1,2,3,33}$ (1) Sandra González-Palacios S $^{1,2,3}$. \\ Miguel Ángel Martínez-González ${ }^{4,5,6}$. Jordi Salas-Salvadó ${ }^{4,7,8,9} \cdot$ Dolores Corella $^{4,10}$. Dolores Zomeño ${ }^{4,11}$. \\ J. Alfredo Martínez ${ }^{4,12,13}$. Ángel M. Alonso-Gómez ${ }^{4,14}$. Julia Wärnberg ${ }^{4,15}$. Dora Romaguera ${ }^{4,16}$. \\ José López-Miranda ${ }^{4,17}$. Ramon Estruch ${ }^{4,18} \cdot$ Rosa M. Bernal-Lopez ${ }^{4,19}$. José Lapetra ${ }^{4,20}$. J. Luís Serra-Majem ${ }^{4,21}$. \\ Aurora Bueno-Cavanillas ${ }^{1,22}$. Josep A. Tur ${ }^{4,23}$. Vicente Martín-Sánchez ${ }^{10,24} \cdot$ Xavier Pintó $^{4,25}$. \\ Miguel Delgado-Rodríguez ${ }^{10,26}$. Pilar Matía-Martín ${ }^{27}$. Josep Vidal ${ }^{28,29} \cdot$ Clotilde Vázquez $^{4,30} \cdot$ Lidia Daimiel $^{31}$. \\ Emili Ros $^{4,32}$. Estefanía Toledo ${ }^{4,5} \cdot$ Nancy Babio ${ }^{4,7,8,9}$. Jose V. Sorli ${ }^{4,10}$. Helmut Schröder ${ }^{1,11}$. María Angeles Zulet ${ }^{4,12}$. \\ Carolina Sorto-Sánchez ${ }^{4,14}$. Francisco Javier Barón-López ${ }^{4,15} \cdot$ Laura Compañ-Gabucio $^{1,2,3} \cdot$ Marga Morey $^{4,16}$. \\ Antonio García-Ríos ${ }^{4,17} \cdot$ Rosa Casas ${ }^{4,18}$ • Ana María Gómez-Pérez ${ }^{4,19}$. José Manuel Santos-Lozano 4,20 . \\ Zenaida Vázquez-Ruiz ${ }^{4,5}$. Stephanie K. Nishi ${ }^{4,7,8,9} \cdot$ Eva M. Asensio $^{4,10}$ - Núria Soldevila ${ }^{1,11}$ - Itziar Abete ${ }^{4,12}$. \\ Leire Goicolea-Güemez ${ }^{4,14}$. Pilar Buil-Cosiales ${ }^{4,5}$. Jesús F. García-Gavilán ${ }^{4,7,8,9}$. Erik Canals ${ }^{1,11}$. \\ Laura Torres-Collado ${ }^{1,2,3} \cdot$ Manuela García-de-la-Hera ${ }^{1,2,3}$
}

Received: 19 May 2021 / Accepted: 19 July 2021 / Published online: 9 August 2021

(c) The Author(s) 2021, corrected publication 2021

\begin{abstract}
Purpose We explored the cross-sectional association between the adherence to three different provegetarian (PVG) food patterns defined as general (gPVG), healthful (hPVG) and unhealthful (uPVG), and the cardiometabolic risk in adults with metabolic syndrome (MetS) of the PREDIMED-Plus randomized intervention study.

Methods We performed a cross-sectional analysis of baseline data from 6439 participants of the PREDIMED-Plus randomized intervention study. The gPVG food pattern was built by positively scoring plant foods (vegetables/fruits/legumes/ grains/potatoes/nuts/olive oil) and negatively scoring, animal foods (meat and meat products/animal fats/eggs/fish and seafood/dairy products). The hPVG and uPVG were generated from the gPVG by adding four new food groups (tea and coffee/fruit juices/sugar-sweetened beverages/sweets and desserts), splitting grains and potatoes and scoring them differently. Multivariable-adjusted robust linear regression using MM-type estimator was used to assess the association between PVG food patterns and the standardized Metabolic Syndrome score (MetS z-score), a composed index that has been previously used to ascertain the cardiometabolic risk, adjusting for potential confounders.

Results A higher adherence to the gPVG and hPVG was associated with lower cardiometabolic risk in multivariable models. The regression coefficients for 5th vs. 1st quintile were -0.16 (95\% CI: -0.33 to 0.01$)$ for gPVG ( $p$ trend: 0.015$)$, and 0.23 (95\% CI: -0.41 to -0.05 ) for hPVG ( $p$ trend: 0.016$)$. In contrast, a higher adherence to the uPVG was associated with higher cardiometabolic risk, 0.21 (95\% CI: 0.04 to 0.38 ) ( $p$ trend: 0.019 ).

Conclusion Higher adherence to gPVG and hPVG food patterns was generally associated with lower cardiovascular risk, whereas higher adherence to uPVG was associated to higher cardiovascular risk.
\end{abstract}

Keywords Dietary food patterns $\cdot$ Cardiometabolic risk $\cdot$ Metabolic syndrome $\cdot$ Pro-vegetarian

\begin{tabular}{|c|c|c|c|}
\hline \multicolumn{2}{|c|}{ Abbreviations } & hPVG & Healthful pro-vegetarian \\
\hline PVG & Pro-vegetarian & uPVG & Unhealthful pro-vegetarian \\
\hline \multirow[t]{2}{*}{ gPVG } & General pro-vegetarian & SUN & Seguimiento Universidad de Navarra \\
\hline & & MetS & Metabolic syndrome \\
\hline \multirow{2}{*}{\multicolumn{2}{|c|}{$\begin{array}{l}\triangle \text { Jesús Vioque } \\
\text { vioque@umh.es }\end{array}$}} & $\begin{array}{l}\text { MetS z-score } \\
\text { CVD }\end{array}$ & $\begin{array}{l}\text { Metabolic syndrome z-score } \\
\text { Cardiovascular disease }\end{array}$ \\
\hline & & Extended author information available on the last page of the article & Diastolic and systolic blood pressure \\
\hline
\end{tabular}




$\begin{array}{ll}\text { BMI } & \text { Body mass index } \\ \text { MedDiet } & \text { Mediterranean diet } \\ \text { T2D } & \text { Type 2 diabetes } \\ \text { FFQ } & \text { Food frequency questionnaire } \\ \text { WHR } & \text { Waist to hip ratio } \\ \text { EDTA } & \text { Ethylene diamine tetraacetic acid } \\ \text { HDL-c } & \text { High density lipoprotein cholesterol } \\ \text { METS } & \text { Metabolic equivalents } \\ \text { SD } & \text { Standard deviation } \\ \text { Q } & \text { Quintile } \\ \text { CI } & \text { Confidence interval } \\ \text { PDI } & \text { Plant-based diet index } \\ \text { uPDI } & \text { Unhealthful plant-based diet index }\end{array}$

\section{Introduction}

Cardiovascular disease (CVD) is the leading cause of premature death and chronic disability worldwide and increases the costs of the healthcare system [1]. Therefore, it is urgent and a priority to provide solutions based on the best scientific evidence for early detection and prevention [2]. Cardiometabolic risk indices or equations are a useful tool to early evaluate CVD risk, and to explore the factors associated with this early onset, thus helping to respond in the short term and to avoid the development of CVD in the long term. These equations take into account the main modifiable risk factors for CVD, such as high blood glucose levels, triglycerides, diastolic and systolic blood pressure (DBP/SBP), body mass index (BMI), waist and hip circumferences and low levels of HDL-c or high levels of LDL-c, to obtain a final score of cardiometabolic risk for each individual.

Diet is another modifiable risk factor of particular interest to public health in relation to cardiometabolic risk [3]. To date, a multitude of studies have focused on exploring the role of diet in CVD from a macronutrient-focused approach, such as low-fat or low-carb diets [4]. However, there is less evidence on the role of a food pattern as a whole, focusing on the consumption of foods and their interactions, and the relationship it could have with cardiovascular risk [5, 6]. The Mediterranean diet (MedDiet) pattern has been one of the most studied food patterns up to now. In a review of 27 studies published by Martínez-González et al., a higher adherence to the MedDiet pattern as measured by the Trichopoulou's index showed an $11 \%$ reduction in the risk of cardiovascular events [7].

The vegetarian diet is another food pattern that has also been recognized for its beneficial effects on numerous health events, such as reducing morbidity including less risk of obesity, hypertension, or type 2 diabetes (T2D), among others, and mortality from chronic diseases [8-12]. This food pattern is characterized by the absence of some animal foods, such as red and processed meats, and a high consumption of plant-based foods, such as fruits, vegetables, legumes or nuts, which could explain its benefits. Thus, while the animal foods might play a harmful role because of their content in certain nutrients (e.g., saturated fat or heme iron), the plant-based foods may have a protective role through antioxidant nutrients (e.g., polyphenols) and fiber [13]. Hence the interest in knowing whether a pro-vegetarian (PVG) food pattern could act as an early marker of cardiometabolic risk may be well justified, especially in nonvegetarian populations. In a cross-sectional analysis of the PREDIMED study, a priori defined PVG index (gPVG) was developed based by positively scoring the consumption of plant-based foods and negatively the consumption of animal origin foods, in 7216 men and women aged 55-80 at high cardiovascular risk, showing a reduction in total mortality [14]. Since not all plant-based foods are equally healthy, Satija et al. subsequently proposed to differentiate between a healthful PVG food pattern (hPVG) which positively scores healthful plant-based foods (fruits, vegetables, legumes, whole grains, nuts, olive oil and coffee), and an unhealthful PVG food pattern (uPVG), which positively scores unhealthful plant-based foods, such as juices, chips, refined cereals, sugary drinks and pastries [15]. A more recently published study carried out with more than 70,000 U.S. women, found that those women with higher adherence to hPVG were less likely to develop coronary heart disease, while those with higher adherence to the uPVG showed a higher risk [16]. In the prospective follow-up study of the University of Navarra (SUN) with 11,554 participants an inverse association between adherence to a hPVG pattern and overweight and obesity was shown [17].

Therefore, it might be of interest to add evidence about the association of increased adherence to PVG patterns on early cardiovascular risk markers as measured by the standardized Metabolic Syndrome score (MetS z-score) and its components, in the context of the PREDIMED-Plus randomized intervention study, which includes participants at high cardiovascular risk and with a low prevalence of vegetarians. This would help to broaden our knowledge of the possible protective role of these food patterns and to propose more healthy dietary recommendations. Thus, the aim of this study was to explore the cross-sectional association between three plant-based diet patterns (gPVG, hPVG and $\mathrm{uPVG}$ ) and MetS z-score, in the adult population of the PREDIMED-Plus study.

\section{Material and methods}

\section{Study population}

The present study is a cross-sectional assessment conducted within the PREDIMED-Plus project (Spain) (www.predi 
medplus.es). This intervention study aims to evaluate the effect of an intensive intervention with weight loss objectives based on the consumption of a low-calorie MedDiet, promotion of physical activity and behavioral therapy in the primary prevention of CVD and has been described in detail elsewhere [18]. Briefly, the participants included in this project were men (55-75 years) and women (60-75 years) with overweight or obesity (BMI $27-40 \mathrm{~kg} / \mathrm{m}^{2}$ ) who meet at least three criteria of the Metabolic Syndrome (MetS) according to the updated criteria of the International Diabetes Federation and the American Heart Association and National Heart, Lung and Blood Institute [19] and without prior cardiovascular events.

Recruitment of participants took place between September 2013 and December 2016 including 6874 participants who were randomized. After excluding participants with missing data for the dietary baseline information, for the parameters necessary to the calculation of MetS z-score and those with implausible values for the mean daily energy intake ( $<500$ and $>3500 \mathrm{kcal} /$ day for women, $<800$ and $>4000 \mathrm{kcal} /$ day for men) [20], 6439 participants were included in the present study (Fig. 1). All participants signed the informed consent, and the project protocol was approved by the Research Ethics Committees from all recruiting centers according to the ethical standards of the Declaration of Helsinki. The trial was registered at the International Standard Randomized Controlled Trial (ISRCTN:http://www. isrctn.com/ISRCTN89898870).

\section{Dietary assessment and pro-vegetarian food patterns}

To obtain the final score of the different PVG patterns, the dietary information was evaluated using a semi-quantitative food frequency questionnaire (FFQ) previously validated in Spain [21, 22]. The FFQ was completed at a baseline visit with the help of a trained interviewer. The FFQ includes a list of 143 foods specifying the standard size or ration of consumption over a period of the previous year including 9 possible responses to determine the frequency of consumption ranging from "never or $<1$ month" to " $\geq 6$ times a day".

For the creation of the gPVG pattern, the methodology proposed by Martínez-González [14] was followed. For healthful and unhealthful PVG versions, the method proposed by Satija et al. [15] was the reference. Dietary information from 18 food groups (Vegetables, Fruits, Legumes, Whole Grains, Refined Grains, Cooked or Roasted Potatoes, Chips, Nuts, Olive Oil, Tea and Coffee, Fruit Juices, Sugary Drinks, Sweets and Desserts, Meat and Meat Products, Animal Fats, Eggs, Fish and Seafood and Dairy) was used. Table 1 specifies the items included in the 18 food groups and the scoring criteria for each pattern.

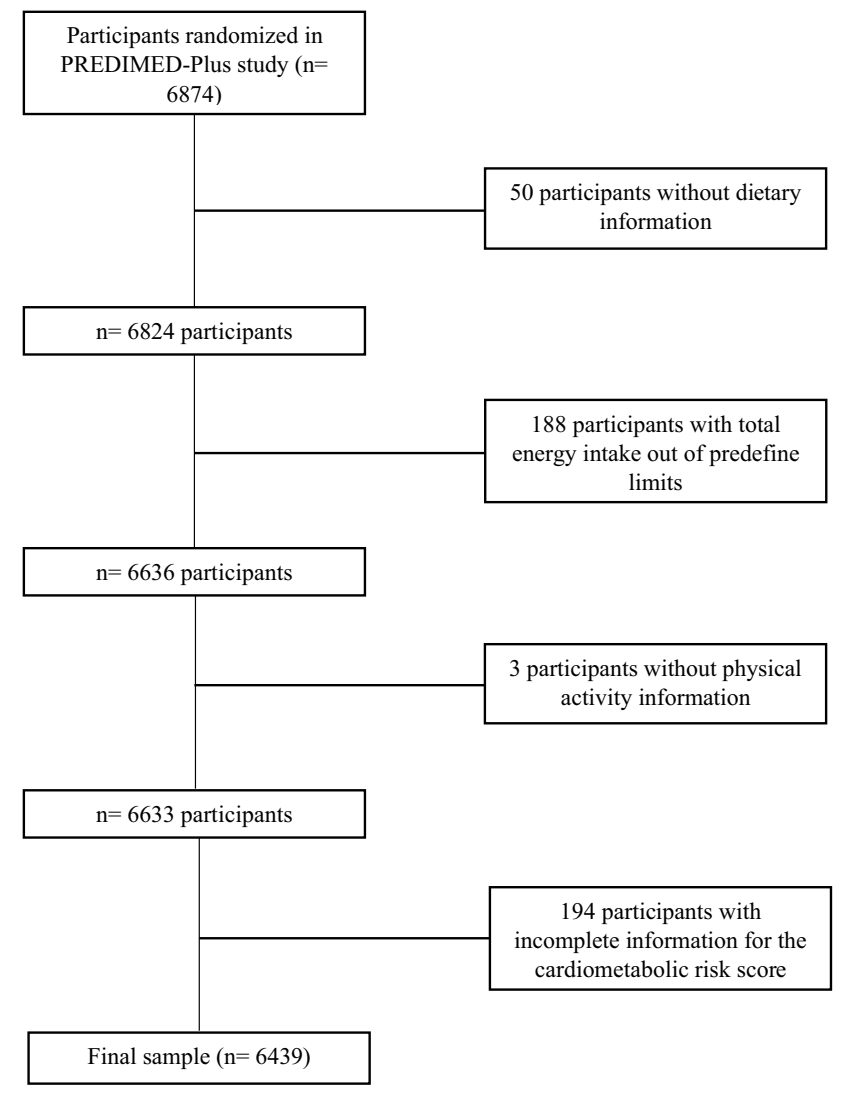

Fig. 1 Flowchart of participants included in the present analysis from the PREDIMED-Plus Study

In short, to create the different PVG food patterns, consumption in grams of the 18 food groups was adjusted for total energy intake following the residual method [23]. After that, calorie-adjusted consumption in grams was categorized into quintiles giving values of $1-5$ according to the consumption quintile of each food group. In the case of the gPVG food pattern seven components, belonging to the plant food groups, scored positively: vegetables, fruits, legumes, grains (whole and refined), potatoes (cooked, roasted and/or fried), nuts and olive oil, and five components (meat and other products, animal fats, eggs, seafood, and dairy), belonging to animal food groups were scored reversely (a value of 5 for lowest consumption). For the hPVG and uPVG, the grain group was separated into whole and refined grains and the potatoes group in fried or chips and cooked or roasted. Four new groups (tea and coffee, natural fruit juices, sweetened drinks and desserts or sweets) were also introduced in both, hPVG and uPVG. To obtain the score of each participant, the points for the 12 components, in the case of the gPVG pattern, and for the 18 groups, in the case of the hPVG and uPVG patterns, were be sum. So, the possible results ranged from 12 points (minimum adherence) to 60 points (maximum adherence) for the gPVG pattern, and 
Table 1 Scoring criteria for the PVG food patterns ${ }^{\mathrm{a}}$

\begin{tabular}{|c|c|c|c|c|}
\hline Component & Included foods & $\mathrm{gPVG}^{\mathrm{c}}$ & hPVG & uPVG \\
\hline \multicolumn{5}{|l|}{ Plant food groups ${ }^{b}$} \\
\hline 1. Vegetables & $\begin{array}{l}\text { Swiss chard, spinach, cauliflower, broccoli, lettuce, tomatoes, carrot, } \\
\text { green beans, zucchini, eggplant, cucumber, peppers, asparagus, } \\
\text { onion, other fresh vegetables }\end{array}$ & Positive & Positive & Reverse \\
\hline 2. Fruits & $\begin{array}{l}\text { Citrus, banana, apple, pear, strawberry, cherry, peach, fig, melon, } \\
\text { watermelon, grapes, kiwi, canned fruit }\end{array}$ & Positive & Positive & Reverse \\
\hline 3. Legumes & Lentils, beans, chickpeas, peas & Positive & Positive & Reverse \\
\hline 4. Whole grains & Whole-grain bread, muesli, brown rice, whole-grain pasta & Positive & Positive & Reverse \\
\hline 5. Refined grains & White bread, breakfast cereals, white rice, white pasta & Positive & Reverse & Positive \\
\hline 6. Potatoes* & Potato chips, French fries, boiled potatoes & Positive & Reverse & Positive \\
\hline 7. Nuts & Almonds, pistachios, walnuts, other nuts & Positive & Positive & Reverse \\
\hline 8. Olive oil & Refined olive oil, extra-virgin olive oil, olive pomace oil & Positive & Positive & Reverse \\
\hline 9. Tea and coffee & Caffeinated coffee, decaffeinated coffee, tea & Not scored & Positive & Reverse \\
\hline 10. Fruit juices & Orange juice, other natural fruits juice & Not scored & Reverse & Positive \\
\hline 11. Sugar-sweetened beverages & $\begin{array}{l}\text { Regular soft drinks, low calorie soft drinks, fruit flavored punch or } \\
\text { noncarbonated beverages }\end{array}$ & Not scored & Reverse & Positive \\
\hline 12. Sweets and desserts & $\begin{array}{l}\text { Cookies, chocolate cookies, whole-grain cookies, home-made cakes } \\
\text { and biscuits, croissant, tea pastries, industrial cakes, donuts, cup- } \\
\text { cake, muffin, chocolate, cocoa powder, nougat, marzipan, sugar }\end{array}$ & Not scored & Reverse & Positive \\
\hline \multicolumn{5}{|l|}{ Animal food groups } \\
\hline 13. Meat/meat products & $\begin{array}{l}\text { Chicken or turkey with or without skin, beef, pork, lamb, rabbit, } \\
\text { liver, viscera, Parma ham, cooked ham, cured meats, salami, mor- } \\
\text { tadella, spicy pork sausage, hot dogs, foie gras, hamburger, bacon }\end{array}$ & Reverse & Reverse & Reverse \\
\hline 14. Animal fats for cooking or as a spread & Butter, lard & Reverse & Reverse & Reverse \\
\hline 15. Eggs & Eggs & Reverse & Reverse & Reverse \\
\hline 16. Fish and other seafood & $\begin{array}{l}\text { White fish, blue fish, salad or smoked fish, clams, squid, shrimp, oil } \\
\text { canned fish, natural canned fish }\end{array}$ & Reverse & Reverse & Reverse \\
\hline 17. Dairy products & $\begin{array}{l}\text { Whole milk, skim or low-fat milk, condensed milk, cream, milk } \\
\text { shake, full fat yogurt, low-fat yogurt, cheese, custard, ice cream }\end{array}$ & Reverse & Reverse & Reverse \\
\hline
\end{tabular}

${ }^{\text {a }}$ Positive indicates that higher consumption of this food group received higher scores. Reverse indicates that higher consumption of this food group received lower scores

${ }^{\mathrm{b}}$ In the hPVG food pattern, whole grains, fruits, vegetables, nuts, legumes, potatoes* (boiled), tea, and coffee were considered "healthy plant foods." Refined grains, French fries and chips*, fruit juices, sugar-sweetened and artificially sweetened beverages, and sweets and desserts were considered "unhealthy plant foods." The gPVG food pattern did not differentiate plant foods as healthy or unhealthy

cIn the gPVG food pattern, consumption of whole grains and refined grains was aggregated as the "grains" food group

from 18 points (minimum adherence) to 90 points (maximum adherence) for the hPVG and uPVG patterns.

\section{MetS z-score and its components}

The continuous cardiometabolic risk scale that we used was the MetS z-score proposed by Franks [24]. Prior to the calculation of this scale, all variables were standardized for the total number of participants, except for HDL and waist to hip ratio (WHR) which were standardized by sex using sexspecific cut-off points. The original version of MetS z-score includes fasting insulin in the formula, but we exclude that parameter from the calculation since it was not measured and determined. We also calculated standardized components of MetS z-score (BMI, WHR, SBP/DBP, HDL-c, plasma triglycerides and plasma glucose).
Weight, height, waist and hip circumference were measured by duplicated with light clothing and no shoes using a calibrate scale, a wall-mounted stadiometer, and a nonelastic tape, respectively. Waist circumference was measured midway between the lowest rib and the iliac crest. Hip circumference was measured at the widest part. BMI was calculated as weight $(\mathrm{kg})$ divided by height (meters) squared, and WHR as waist circumference (in $\mathrm{cm}$ ) divided by hip circumference (in $\mathrm{cm}$ ). Blood pressure was measured three times with a validated semiautomatic oscillometer after 5 min of rest in-between measurement (Omron HEM$705 \mathrm{CP}$, Hoofddorp, The Netherlands), and the mean of the three measurements was used. After an overnight fast, blood samples were collected at baseline and aliquots of serum and ethylene diamine tetraacetic acid (EDTA) plasma were immediately processed, coded and stored at $-80{ }^{\circ} \mathrm{C}$ in a 
central laboratory until analysis. High Density Lipoprotein (HDL), serum glucose and triglyceride levels were determined by standard enzymatic methods in automatic analyzers in local laboratories.

The MetS z-score for each participant was obtained using the following formula:

$(\mathrm{BMI}+\mathrm{WHR}) / 2+(\mathrm{SBP}+\mathrm{DBP}) / 2+$ hyperglycemia (plasma fasting glucose)-HDLc + triglycerides

\section{Covariates}

Other sociodemographic variables, lifestyles and previous history of various diseases, as well as assigned intervention, was also collected at baseline. Information about total physical activity in Metabolic Equivalents (METS) min/day was measured using the validated Regicor Short Physical Activity Questionnaire [25]. Adherence to MedDiet was valued with a 17-item questionnaire, a modified version of a previously validated 14-item questionnaire [26], for an energyrestricted version.

\section{Statistical analysis}

Descriptive analysis of participants' characteristics according to quintiles of each PVG food pattern adherence was shown as mean and standard deviation (SD) for quantitative traits, and percentage for categorical variables. We performed the ANOVA test for quantitative variables and the Chi-square test for qualitative variables to compare the characteristics of the sample between adherence quintiles.

Multiple robust linear regression models were performed using an MM-type estimator by adjusting for possible confounders to explore the association between adherence to each PVG food pattern (in quintiles and per 5 points increment in adherence) and MetS z-score, along and with its components separately [27]. Regression coefficients represent the change in each outcome, where 1 unit is equivalent to a 1-SD difference in $\mathrm{z}$ scores, or a 1-unit difference in the MetS z-score or its components, per one point of dietary adherence to PVG food patterns, either in the continuous (per each 5 points of adherence) or quintiles form of the different PVG food patterns.

Possible confounder selection was based on a previous review of the literature. It was also adjusted by those variables that when estimating the effect of exposure, the effect changed by $\geq 10 \%$ when excluding the variable from the model. Crude model was minimally adjusted for energy intake. Model 1 was additionally adjusted for age (continuous) and sex. Model 2 was additionally adjusted for educational level (illiterate or primary education, secondary education, academic or graduate, and missing information), smoking status (current smoker, former smoker, and never smoker), alcohol intake (grams/day) and total physical activity per day (METS-min/day).

Statistical analyses were carried out with R 3.5.1 (R Foundation for Statistical Computing, Vienna, Austria; http://www.R-project.org). For robust linear regression analyses, we also used a robust base package of statistical software R. We used the database version of the PREDIMED-Plus dated March 2019.

\section{Results}

Baseline characteristics of participants according to quintiles of the three PVG food patterns are presented in Table 2. Participants with a higher adherence to gPVG and hPVG patterns were more likely to be older, more physically active, have a lower BMI and better adhere to the MedDiet pattern. Inversely, those participants with a higher adherence to the uPVG pattern were more likely to be younger, smoker, less physically active and less adherent to the MedDiet. Lower education and lower alcohol consumption were observed in those participants with higher adherence to the gPVG pattern, and a higher alcohol consumption in more adhered participants to hPVG and uPVG patterns. Diabetes prevalence was lower in participants with a higher adherence to uPVG pattern.

The results of the multiple robust linear regression analysis for the association between the different PVG patterns (in quintiles of adherence and in continuous for every 5 points) and the score of MetS with its components separately are presented in Tables 3, 4 and 5. Reduction in MetS score and its components separately is shown in units of SD according to quintiles of adherence for the PVG food patterns $(p$ trend $<0.001)$. After adjusting for energy intake, sex, age, educational level, smoking status, alcohol intake and total physical activity per day, we observed a reduction in the global MetS z score (regression coefficient, ' $\beta$ ' for fifth quintile $(\mathrm{Q} 5)$ vs. first quintile $(\mathrm{Q} 1)=-0.16$; $95 \%$ CI: -0.33 to $0.01 ; p$-trend: 0.015 ), the BMI ( $\beta$ for Q5 vs $\mathrm{Q} 1=-0.14 ; 95 \%$ CI: -0.22 to $-0.06 ; p$ trend: $<0.001)$ and the WHR ( $\beta$ for Q5 vs Q1 $=-0.16$; 95\% CI: -0.23 to $-0.09 ; p$ trend: $<0.001)$ in those participants with "very high" adherence ( $>40$ points) to the gPVG pattern (Table 3 ). Also, we observed direct associations with DBP ( $\beta$ for Q5 vs $\mathrm{Q} 1=0.11$; $95 \%$ CI: 0.03 to 0.18 ; $p$ trend: 0.009$)$ and HDLcholesterol ( $\beta$ for $\mathrm{Q} 5$ vs $\mathrm{Q} 1=0.07 ; 95 \%$ CI: 0.00 to $0.14 ; p$ trend: 0.046 ) in the fully adjusted gPVG food pattern model. When the gPVG pattern was considered as continuous variable (every 5 points of increment) we observed inverse associations with BMI $\beta=-0.06$ (95\% CI: $-0.09 ;-0.04)$ and WHR $\beta=-0.06$ (95\% CI: $-0.08 ;-0.03)$. On the other hand, we observed a direct association with DBP $\beta=0.03$ (95\% CI: $0.01 ; 0.06)$. 
Table 2 Baseline characteristics of participants according to quintiles of the three PVG food patterns: the PREDIMED-Plus Study ( $n=6439)$

\begin{tabular}{|c|c|c|c|c|c|}
\hline & \multicolumn{5}{|c|}{ gPVG food pattern ${ }^{a}$} \\
\hline & $\begin{array}{l}\text { Very low: }<33 \\
(n=1589)\end{array}$ & $\begin{array}{l}\text { Low: } 33-35 \\
(n=1345)\end{array}$ & $\begin{array}{l}\text { Moderate: } 36-37 \\
(n=980)\end{array}$ & $\begin{array}{l}\text { High: } 38-40 \\
(n=1297)\end{array}$ & $\begin{array}{l}\text { Very High: }>40 \\
(n=1228)\end{array}$ \\
\hline Sex, male $(\%)$ & 52.1 & 52.2 & 51.0 & 50.9 & 52.1 \\
\hline Age $(y)$ & $64.4(5.0)^{\mathrm{b}}$ & $64.7(4.8)$ & $65.2(4.9)$ & $65.4(4.9)$ & $65.5(4.9)$ \\
\hline Illiterate or primary education (\%) & 44.6 & 48.0 & 50.3 & 52.4 & 52.6 \\
\hline Hypertension (\%) & 83.8 & 82.8 & 84.4 & 82.7 & 84.0 \\
\hline High blood cholesterol (\%) & 69.4 & 70.3 & 67.6 & 70.0 & 69.3 \\
\hline Diabetes (\%) & 31.4 & 32.6 & 32.4 & 28.0 & 29.7 \\
\hline BMI $\left(\mathrm{Kg} / \mathrm{m}^{2}\right)$ & $32.8(3.5)$ & $32.8(3.5)$ & $32.4(3.4)$ & $32.3(3.5)$ & $32.3(3.3)$ \\
\hline Smoking ( $\%$ current smokers) & 14.7 & 11.6 & 11.6 & 12.6 & 12.7 \\
\hline Alcohol intake $(\mathrm{g} / \mathrm{d})$ & $11.8(15.6)$ & $11.5(15.1)$ & $10.6(15.0)$ & $11.0(15.1)$ & $10.3(14.4)$ \\
\hline Physical activity (MET-min/d) ${ }^{\mathrm{c}}$ & $326.3(311.3)$ & $332.3(330.4)$ & $357.6(314.8)$ & $360.6(335.5)$ & $394.0(353.4)$ \\
\hline \multirow{3}{*}{$\begin{array}{l}\text { Adherence to Mediterranean diet } \\
(0-17 \text { points })^{\mathrm{d}}\end{array}$} & $7.8(2.6)$ & $8.3(2.6)$ & $8.6(2.5)$ & $8.8(2.6)$ & $9.3(2.7)$ \\
\hline & \multicolumn{5}{|c|}{ hPVG food pattern } \\
\hline & $\begin{array}{l}\text { Very low: }<49 \\
(n=1454)\end{array}$ & $\begin{array}{l}\text { Low: } 49-52 \\
(n=1231)\end{array}$ & $\begin{array}{l}\text { Moderate: } 53-56 \\
(n=1391)\end{array}$ & $\begin{array}{l}\text { High: } 57-60 \\
(n=1241)\end{array}$ & $\begin{array}{l}\text { Very high: }>60 \\
(n=1122)\end{array}$ \\
\hline Sex, male $(\%)$ & 52.3 & 49.3 & 51.8 & 54.4 & 50.6 \\
\hline Age (y) & $64.5(5.0)$ & $64.7(4.9)$ & $65.1(4.8)$ & $65.4(4.9)$ & $65.5(4.8)$ \\
\hline Illiterate or primary education (\%) & 49.1 & 50.0 & 50.1 & 48.5 & 48.7 \\
\hline Hypertension (\%) & 84.4 & 84.0 & 83.9 & 83.5 & 81.2 \\
\hline High blood cholesterol (\%) & 70.2 & 69.5 & 69.7 & 67.8 & 69.9 \\
\hline Diabetes (\%) & 32.1 & 29.7 & 29.2 & 32.2 & 30.8 \\
\hline $\mathrm{BMI}\left(\mathrm{Kg} / \mathrm{m}^{2}\right)$ & $32.8(3.5)$ & $32.6(3.4)$ & $32.5(3.4)$ & $32.3(3.4)$ & $32.4(3.4)$ \\
\hline Smoking (\% current smokers) & 14.1 & 13.7 & 11.4 & 12.3 & 12.2 \\
\hline Alcohol intake (g/d) & $9.9(13.3)$ & $10.4(14.6)$ & $11.6(15.8)$ & $11.6(15.2)$ & $12.3(16.6)$ \\
\hline Physical activity (MET-min/d) & $303.9(307.1)$ & $332.5(315.0)$ & $348.1(319.6)$ & $379.1(335.0)$ & $411.4(367.8)$ \\
\hline \multirow{3}{*}{$\begin{array}{l}\text { Adherence to Mediterranean diet } \\
(0-17 \text { points })^{\mathrm{d}}\end{array}$} & $7.2(2.4)$ & $8.2(2.5)$ & $8.5(2.4)$ & $9.1(2.5)$ & $10.0(2.6)$ \\
\hline & \multicolumn{5}{|c|}{ uPVG food pattern } \\
\hline & $\begin{array}{l}\text { Very low: }<49 \\
(n=1504)\end{array}$ & $\begin{array}{l}\text { Low: } 49-52 \\
(n=1197)\end{array}$ & $\begin{array}{l}\text { Moderate: } 53-56 \\
(n=1288)\end{array}$ & $\begin{array}{l}\text { High: } 57-60 \\
(n=1192)\end{array}$ & $\begin{array}{l}\text { Very high: }>60 \\
(n=1258)\end{array}$ \\
\hline Sex, male $(\%)$ & 51.1 & 51.5 & 51.6 & 53.9 & 50.7 \\
\hline Age (y) & $65.7(4.9)$ & $64.7(4.9)$ & $65.1(4.9)$ & $64.7(4.8)$ & $64.6(5.0)$ \\
\hline Illiterate or primary education (\%) & 48.1 & 48.0 & 49.5 & 49.8 & 51.2 \\
\hline Hypertension (\%) & 82.2 & 84.0 & 84.6 & 83.7 & 83.0 \\
\hline High blood cholesterol (\%) & 69.9 & 67.8 & 69.8 & 70.1 & 69.2 \\
\hline Diabetes (\%) & 37.3 & 30.2 & 31.1 & 26.8 & 27.0 \\
\hline $\mathrm{BMI}\left(\mathrm{Kg} / \mathrm{m}^{2}\right)$ & $32.4(3.4)$ & $32.5(3.5)$ & $32.6(3.4)$ & $32.6(3.4)$ & $32.6(3.5)$ \\
\hline Smoking (\% current smoker) & 10.4 & 11.7 & 13.5 & 13.2 & 15.6 \\
\hline Alcohol intake (g/d) & $8.6(11.8)$ & $10.8(14.0)$ & $11.6(15.8)$ & $12.3(16.4)$ & $12.7(17.0)$ \\
\hline Physical activity (MET-min/d) & $396.7(344.6)$ & $374.6(356.3)$ & $352.5(320.1)$ & 330.5 (306.6) & $297.7(307.1)$ \\
\hline $\begin{array}{l}\text { Adherence to Mediterranean diet } \\
(0-17 \text { points })^{\mathrm{d}}\end{array}$ & $10.0(2.5)$ & $9.1(2.5)$ & $8.5(2.5)$ & $7.7(2.3)$ & $7.0(2.4)$ \\
\hline
\end{tabular}

${ }^{a}$ Comparisons of characteristics across quintiles of the PVG food patterns were performed using 1-factor ANOVA for quantitative variables or chi-square tests for categorical variables

${ }^{\mathrm{b}}$ Mean (SD) (all such values)

${ }^{\mathrm{c}}$ MET-min metabolic equivalent task minutes

${ }^{\mathrm{d}}$ Adherence to an energy-restricted MedDiet was assessed using a 17-item questionnaire, a modified version of a validated 14-item questionnaire [26] 


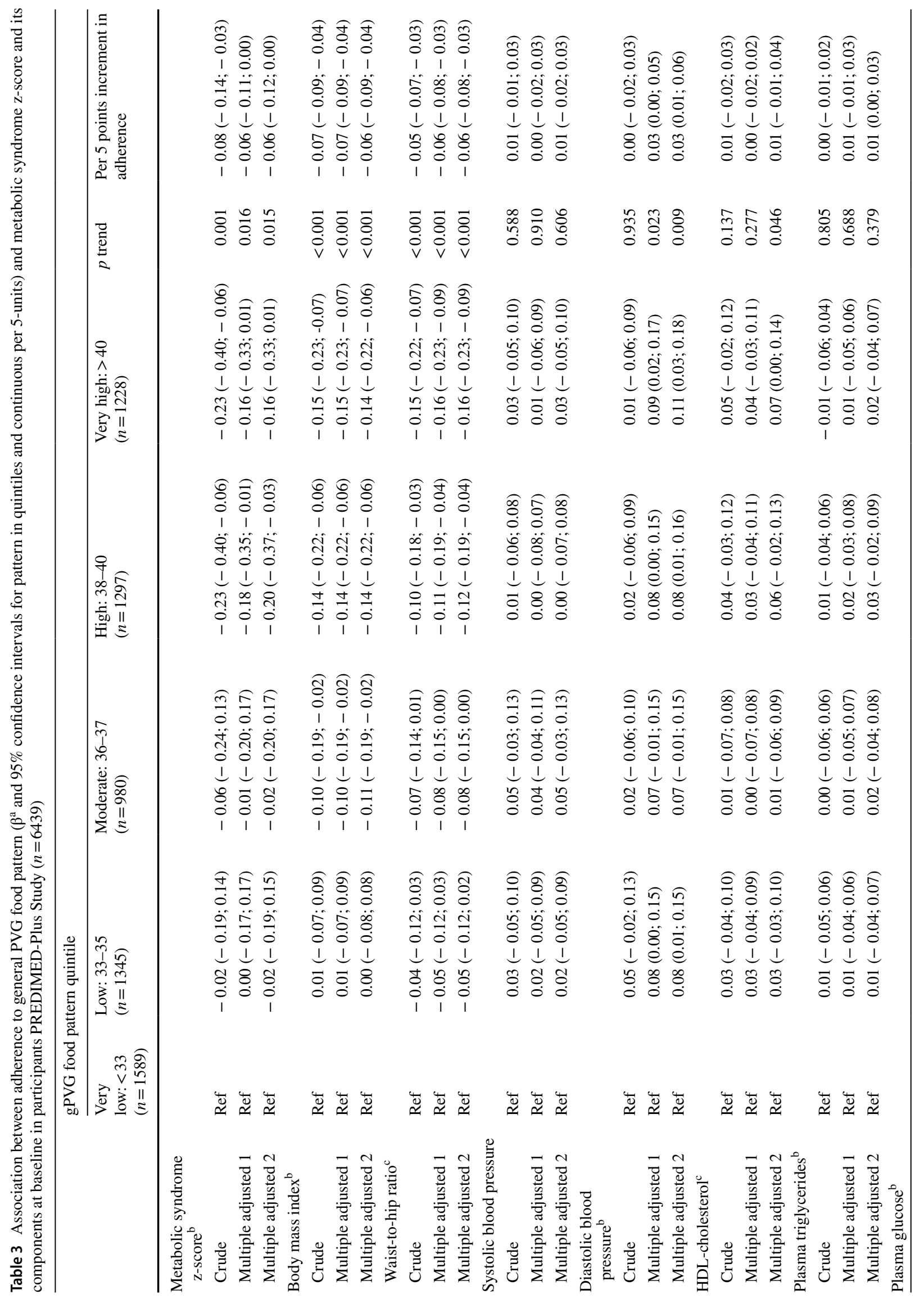




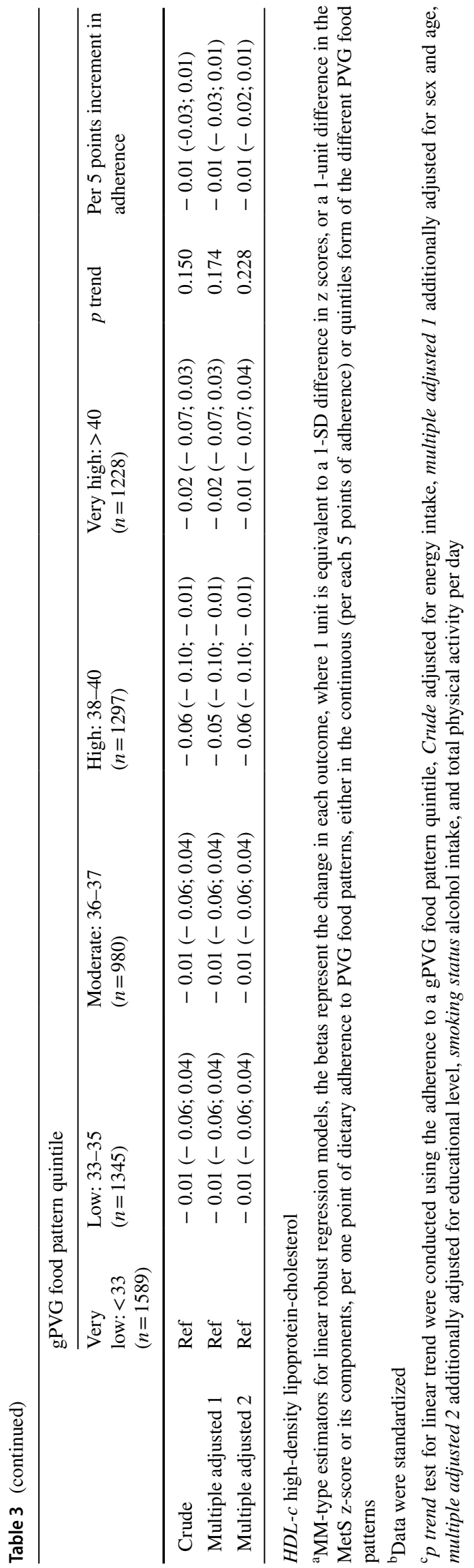

When we specifically assessed the hPVG version, the associations were stronger. For the fully adjusted models (Table 4), the hPVG was associated with lower MetS $\mathrm{z}$-scores ( $\beta$ for Q5 vs Q1 $=-0.23$; 95\% CI: -0.41 to -0.05 ; $p$ trend: 0.016 ), BMI ( $\beta$ for Q5 vs $\mathrm{Q} 1=-0.07 ; 95 \% \mathrm{CI}$ : -0.15 to $0.02 ; p$ trend: 0.043 ) and WHR ( $\beta$ for Q5 vs $\mathrm{Q} 1=-0.14 ; 95 \% \mathrm{CI}:-0.22$ to $-0.07 ; p$ trend: $<0.001$ ). We also observed inverse associations between the adherence to hPVG (per 5 points of increment) and MetS z-score, $\beta=-0.06$ (95\% CI: $-0.10 ;-0.02)$ and WHR $\beta=-0.04$ (95\% CI: - 0.05; - 0.02).

By contrast, in the fully adjusted models for the uPVG (Table 5) we observed a significant positive association with the MetS z-score ( $\beta$ for Q5 vs Q1 $=0.21 ; 95 \%$ CI: 0.04 to 0.38 ; $p$ trend: 0.019 ), DBP ( $\beta$ for $\mathrm{Q} 5$ vs $\mathrm{Q} 1=0.08 ; 95 \% \mathrm{CI}$ : 0.00 to $0.15 ; p$ trend: 0.042 ) and plasma triglycerides ( $\beta$ for Q5 vs Q1 $=0.08$; 95\% CI: 0.02 to 0.13 ; $p$ trend: 0.003$)$. In addition, we observed an inverse association with HDL-cholesterol ( $\beta$ for Q5 vs Q1 $=-0.11$; 95\% CI: -0.18 to -0.04 ; $p$ trend: 0.001$)$ and plasma glucose $(\beta$ for $\mathrm{Q} 5$ vs $\mathrm{Q} 1=-0.07$; 95\% CI: -0.12 to $-0.02 ; p$ trend: 0.002 ). In the models with continuous variables, we also observed inverse associations per each 5 points increases in adherence to the uPVG of $\beta=-0.02$ (95\% CI: $-0.04 ;-0.01)$ for HDL-cholesterol and $\beta=-0.02$ (95\% CI: $-0.03 ;-0.01)$ plasma glucose, and direct associations of $\beta=0.02$ (95\% CI: $0.01 ; 0.03$ ) for plasma triglycerides.

\section{Discussion}

The results of this study suggest that adults with MetS and a higher adherence to the general and hPVG food patterns showed more favorable cardiometabolic markers as measured by the MetS z-score and several of its components. On the contrary, those participants with higher adherence to the uPVG food pattern showed worse cardiometabolic markers.

Although the research about these food patterns is relatively recent, several studies have shown consistent results. A prospective cohort study in South Korean investigated the role of being adherent to four plant-based diet indices (PDI) and found a positive linear association between higher adherence to an unhealthful plant-based diet (UPDI) and the incidence of MetS [28]. In the Adventist Health Study 2, a prospective study with 96,000 participants of the Seventh-day Adventist church mostly following vegetarian diets, positive associations were found between vegetarian diets and all components of metabolic syndrome (triglycerides, DBP, SBP, waist circumference, BMI and glucose), although not so for HDL-c [29]. Two other prospective cohort studies in the USA and Spain have also found beneficial associations for weight change in the case 


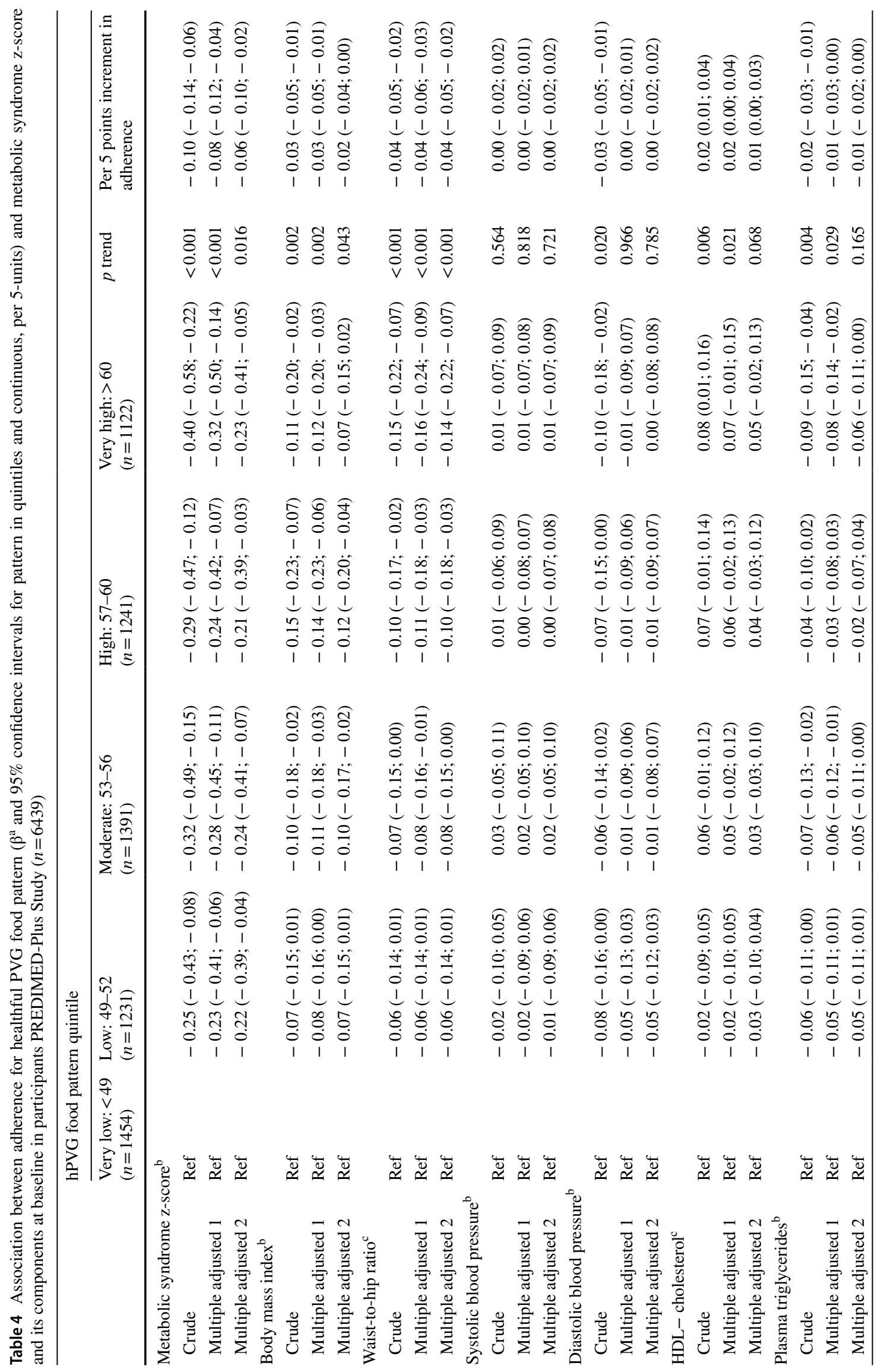




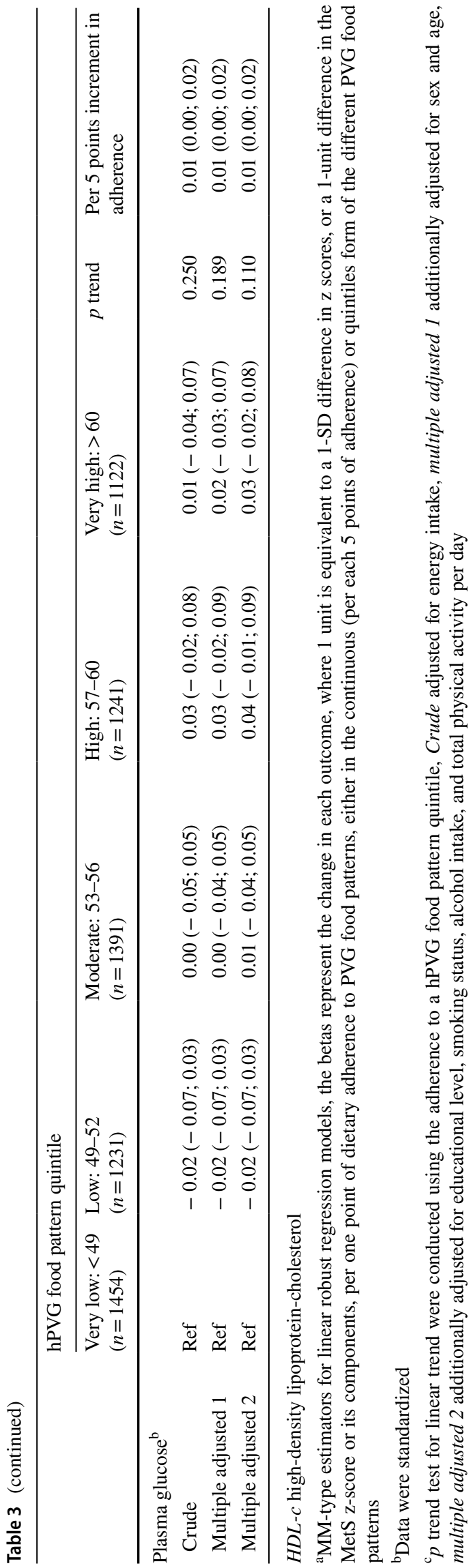

of the gPVG and hPVG food patterns [17, 30], in line with our findings for BMI.

The beneficial effect of a PVG food pattern might extend beyond the improvement in cardiometabolic markers. In a previous research of 12,168 middle-aged adults in South Korea (45-64 years of age at baseline), a higher adherence to a healthful PDI index and PVG patterns was associated to lower risk of cardiovascular morbidity and mortality, and lower all-cause mortality [31]. A lower all-cause mortality was also reported for those with a gPVG food pattern in an older population of the PREDIMED study [14].

Participants with better adherence to uPVG food pattern showed lower plasma glucose concentrations in our study. This type of inverse association between uPDI food pattern and risk of T2D has been also shown previously [15]. An explanation for this unexpected association could be some reverse causation, in the sense that those subjects with a T2D diagnosis were more aware of sugar content in different food groups and for this reason we observed lower prevalence of T2D among those better adhering a uPVG food pattern.

The mechanisms by which PVG food patterns could have cardiometabolic beneficial effects are multiple, likely related to the high content of plant-based foods with low glycemic index [32]. A higher intake of plant foods like fruits, vegetables, nuts, legumes or whole grains, leads to a higher intake of different bioactive compounds such as fiber which has been associated with greater satiation and consequently, a lower energy intake and body weight [33]. Moreover, the consumption of different types of fiber can modulate and improve glucose homeostasis by different mechanisms such as a delay of gastric emptying with consequent reduction in glucose absorption or via its fermentation in the colon, that produces short-chain fatty acids, which may reduce glucose formation in hepatocytes $[34,35]$. Other components of plant foods such as polyphenols or stanols, can reduce the endogen pathways of lipids formation. As shown in a systematic review and meta-analysis of observational and intervention studies, plant-based diets have been consistently associated with lower blood lipid levels such as total cholesterol, c-LDL and c-HDL [36]. Nitric oxide is another substance that we produce when take a sunlight bath or with the ingestion of some nutrients present in plant foods, like the amino acid L-arginine present in seeds and nuts [37] or nitrates present in various vegetables including beets [38], which could improve blood pressure and endothelial and platelet function through different mechanism.

Conversely, uPVG may increase cardiometabolic risk because some of its components, such as chips, sugar-sweetened beverages, sugary desserts, sweets, are rich in added sugars, sodium, poor quality fats, refined starches and flavor enhancers. Many of these foods usually belong to ultra-processed food groups that could damage our internal systems, 


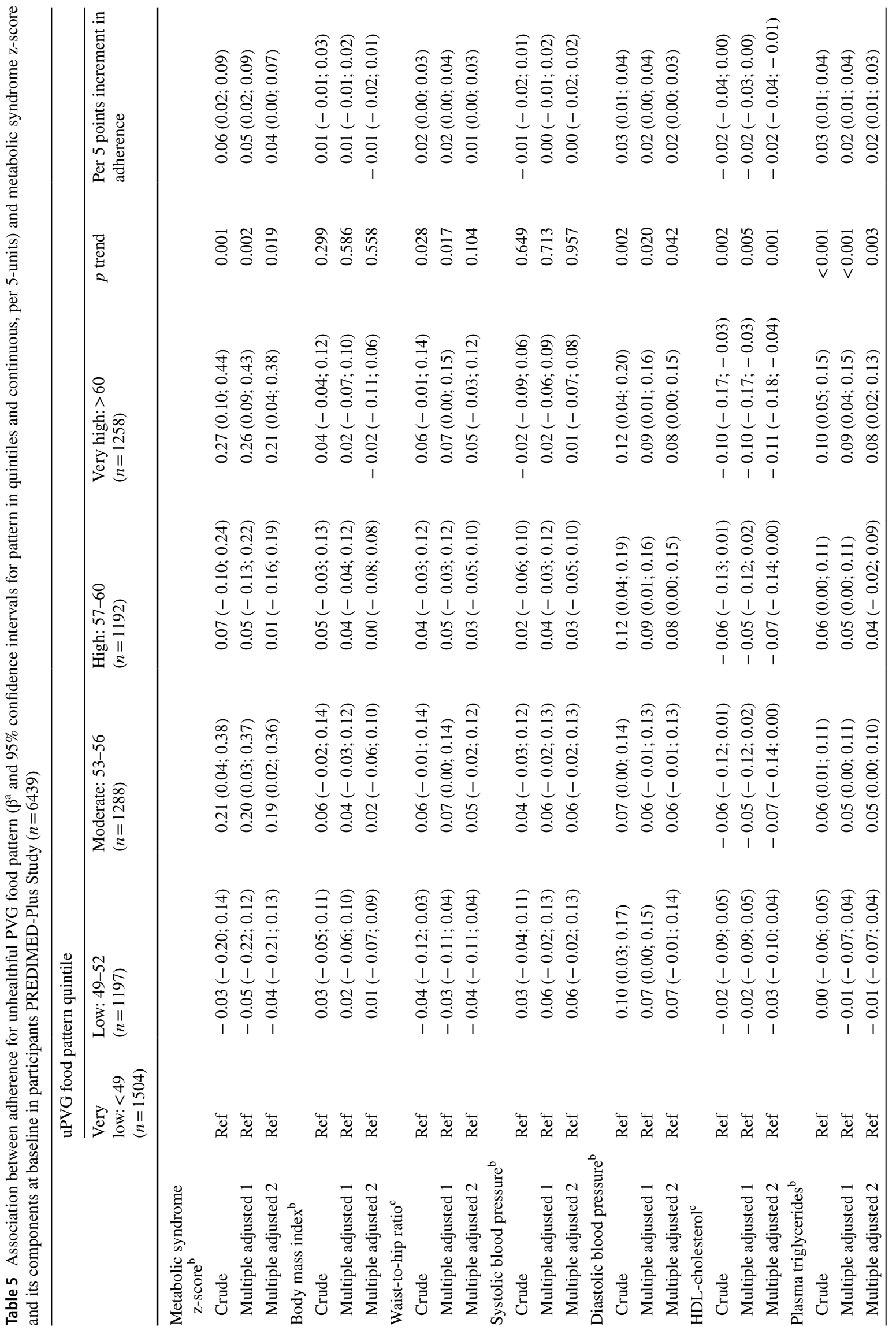


worsening our glucose homeostasis, increasing our blood pressure and modifying the ratio of blood lipids to a pattern of increased cardiometabolic risk, regardless of whether they come from plants or animals [39-41].

Apart from the potential beneficial effects of PVG food patterns, we should consider their environmental consequences. Thus, in one analysis performed in the SUN Project which compared this pattern with other options as MedDiet or Western Diet, despite the fact that MedDiet presents the relatively lowest environmental footprint, gPVG food pattern was the ecofriendliest pattern and with the additional advantage of being more affordable when compared to MedDiet [42].

We acknowledge that our study has several limitations. First, cross-sectional studies have a limited capacity to establish causality, and may be prone to reverse causation as that mentioned above for the inverse association between uPVG and T2D. However, there are previous studies, some of them with prospective design, that showed results in the same direction as our findings. Second, we took into account in the analyses several confounders such as sociodemographic or lifestyle variables, but there may be other potential confounders not accounted for that may influence cardiometabolic risk. Another limitation is our diet measurement instrument. Although it was a validated instrument, it refers to the usual intake over the previous year and therefore makes it difficult to draw conclusions about the longer-term effects of the diet on cardiometabolic risk. Another limitation of our study concerns the study population, elderly people with metabolic syndrome and without prior cardiovascular events, which make it difficult to extrapolate results to other healthy or dissimilar populations. Thus, it is desirable to replicate our results in future studies with different populations.

Our study has also strengths. The quality and quantity of information that we measured is high thanks to our trained personal and the robustness of our findings, that were maintained after adjusted the models for possible confounders. Additionally, the use of three plant-based dietary patterns with a better assignment of several specific foods helped us to distinguish that not all vegetarian patterns are as beneficial as supposed to be. Our findings may also help to clarify some inconsistencies in the literature and to determine which type of dietary recommendations may be most beneficial when following a PVG pattern to reduce the overall MetS risk.

In conclusion, this study suggests that among older adults at high cardiometabolic risk, a greater adherence to general and hPVG food patterns are associated with lower cardiometabolic risk, while a greater adherence to uPVG food pattern is associated with a higher cardiometabolic risk. Further studies are recommended to investigate if these associations are also observed in other healthy populations.

Acknowledgements We thank all Predimed-Plus participants and investigators. CIBEROBN, CIBERESP, and CIBERDEM are initiatives 
of the Instituto de Salud Carlos III (ISCIII), Madrid, Spain. The Hojiblanca (Lucena, Spain) and Patrimonio Comunal Olivarero (Madrid, Spain) food companies donated extra-virgin olive oil. The Almond Board of California (Modesto, CA), American Pistachio Growers (Fresno, CA), and Paramount Farms (Wonderful Company, LLC, Los Angeles, CA) donated nuts.

Author's contributions AOC and JV conducted the statistical analyses and drafted the article. All authors contributed substantially to the acquisition of data or analysis and interpretation of data. All authors revised the article critically for important intellectual content. All authors approved the final version to be published.

Funding Open Access funding provided thanks to the CRUE-CSIC agreement with Springer Nature. This work was supported by the official Spanish Institutions for funding scientific biomedical research, CIBER Fisiopatología de la Obesidad y Nutrición (CIBEROBN) and Instituto de Salud Carlos III (ISCIII), through the Fondo de Investigación para la Salud (FIS), which is co-funded by the European Regional Development Fund (six coordinated FIS projects leaded by JS-S and JVi, including the following projects: PI13/00673, PI13/00492, PI13/00272, PI13/01123, PI13/00462, PI13/00233, PI13/02184, PI13/00728, PI13/01090, PI13/01056, PI14/01722, PI14/00636, PI14/00618, PI14/00696, PI14/01206, PI14/01919, PI14/00853, PI14/01374, PI14/00972, PI14/00728, PI14/01471, PI16/00473, PI16/00662, PI16/01873, PI16/01094, PI16/00501, PI16/00533, PI16/00381, PI16/00366, PI16/01522, PI16/01120, PI17/00764, PI17/01183, PI17/00855, PI17/01347, PI17/00525, PI17/01827, PI17/00532, PI17/00215, PI17/01441, PI17/00508, PI17/01732, PI17/00926, PI19/00957, PI19/00386, PI19/00309, PI19/01032, PI19/00576, PI19/00017, PI19/01226, PI19/00781, PI19/01560, PI19/01332, PI20/01802, PI20/00138, PI20/01532, PI20/00456, PI20/00339, PI20/00557, PI20/00886, PI20/01158); the Especial Action Project entitled: Implementación y evaluación de una intervención intensiva sobre la actividad física Cohorte PREDIMED-Plus grant to JS-S; the European Research Council (Advanced Research Grant 2014-2019; agreement \#340918) granted to MÁMG.; the Recercaixa (number 2013ACUP00194) grant to JS-S; grants from the Consejería de Salud de la Junta de Andalucía (PI0458/2013, PS0358/2016, PI0137/2018); the PROMETEO/2017/017 grant from the Generalitat Valenciana; the SEMERGEN grant; None of the funding sources took part in the design, collection, analysis, interpretation of the data, or writing the report, or in the decision to submit the manuscript for publication.

\section{Declarations}

Conflict of interest J.S.-S. reported receiving research support from the Instituto de Salud Carlos III, Ministerio de Educación y Ciencia, Departament de Salut Pública de la Generalitat de Catalunya, the European Commission, the USA National Institutes of Health; receiving consulting fees or travel expenses from Danone, California Walnut Commission, Eroski Foundation, Instituto Danone, Nestle, and Abbott Laboratories, receiving nonfinancial support from Hojiblanca, Patrimonio Comunal Olivarero, the California Walnut Commission, Almond Board of California, La Morella Nuts, Pistachio Growers and Borges S.A; serving on the board of and receiving grant support through his institution from the International Nut and Dried Foundation and the Eroski Foundation; and grants and personal fees from Instituto Danone; Serving in the Board of Danone Institute International. D.C. reported receiving grants from Instituto de Salud Carlos III. R.E. reported receiving grants from Instituto de Salud Carlos III, Fundación Dieta Meditarránea and Cerveza y Salud and olive oil for the trial from Fundación Patrimonio Comunal Olivarero and personal fees from Brewers of Europe, Fundación Cerveza y Salud, Interprofesional del Aceite de Oliva,
Instituto Cervantes in Albuquerque, Milano and Tokyo, Pernod Ricard, Fundación Dieta Mediterránea (Spain), Wine and Culinary International Forum and Lilly Laboratories; non-financial support from Sociedad Española de Nutrición and Fundación Bosch y Gimpera; and grants from Uriach Laboratories. E.R. reports grants, personal fees, non-financial support and other from California Walnut Commission, during the conduct of the study; grants, personal fees, non-financial support and other from Alexion; grants from Amgen and Pfizer; grants, personal fees and other from Sanofi Aventis; personal fees, non-financial support and other from Ferrer International, Danone and Merck Sharp \& Dohme, personal fees and other from Amarin, outside the submitted work. S.K.N. received research support from a Canadian Institutes of Heath Research and is a volunteer member of the non-for-profit group Plant Based Canada. The rest of the authors have declared that no competing interests exist. The funders had no role in the design of the study; in the collection, analyses, or interpretation of data; in the writing of the manuscript, or in the decision to publish the results.

Open Access This article is licensed under a Creative Commons Attribution 4.0 International License, which permits use, sharing, adaptation, distribution and reproduction in any medium or format, as long as you give appropriate credit to the original author(s) and the source, provide a link to the Creative Commons licence, and indicate if changes were made. The images or other third party material in this article are included in the article's Creative Commons licence, unless indicated otherwise in a credit line to the material. If material is not included in the article's Creative Commons licence and your intended use is not permitted by statutory regulation or exceeds the permitted use, you will need to obtain permission directly from the copyright holder. To view a copy of this licence, visit http://creativecommons.org/licenses/by/4.0/.

\section{References}

1. Roth GA, Mensah GA, Johnson CO, GBD-NHLBI-JACC Global Burden of Cardiovascular Diseases Writing Group (2020) Global burden of cardiovascular diseases and risk factors, 1990-2019: update from the GBD 2019 study. J Am Coll Cardiol 76:29823021. https://doi.org/10.1016/j.jacc.2020.11.010

2. Von Bibra H, Paulus W, St John Sutton M (2016) Cardiometabolic syndrome and increased risk of heart failure. Curr Heart Fail Rep 13:219-229. https://doi.org/10.1007/s11897-016-0298-4

3. Pérez-Martínez P, Mikhailidis DP, Athyros VG et al (2017) Lifestyle recommendations for the prevention and management of metabolic syndrome: an international panel recommendation. Nutr Rev 75:307-326. https://doi.org/10.1093/nutrit/nux014

4. Hu T, Mills KT, Yao L et al (2012) Effects of low-carbohydrate diets versus low-fat diets on metabolic risk factors: a meta-analysis of randomized controlled clinical trials. Am J Epidemiol 176(Suppl 7):S44-54. https://doi.org/10.1093/aje/kws264

5. Hu FB (2002) Dietary pattern analysis: a new direction in nutritional epidemiology. Curr Opin Lipidol 13:3-9. https://doi.org/ 10.1097/00041433-200202000-00002

6. Mozaffarian D (2016) Dietary and policy priorities for cardiovascular disease, diabetes, and obesity: a comprehensive review. Circulation 133:187-225. https://doi.org/10.1161/CIRCULATIO NAHA.115.018585

7. Martínez-González MÁ, Hershey MS, Zazpe I, Trichopoulou A (2017) Transferability of the mediterranean diet to non-mediterranean countries what is and what is not the mediterranean diet. Nutrients 9:1226. https://doi.org/10.3390/nu9111226 (pii:1226)

8. Yokoyama Y, Nishimura K, Barnard ND et al (2014) Vegetarian diets and blood pressure: a meta-analysis. JAMA Intern Med 174:577-587. https://doi.org/10.1001/jamainternmed.2013.14547 
9. Huang RY, Huang CC, Hu FB et al (2016) Vegetarian diets and weight reduction: a meta-analysis of randomized controlled trials. J Gen Intern Med 31:109-116. https://doi.org/10.1007/ s11606-015-3390-7

10. Lee Y, Park K (2017) Adherence to a vegetarian diet and diabetes risk: a systematic review and meta-analysis of observational studies. Nutrients 9: pii: E603. https://doi.org/10.3390/nu9060603

11. Dinu M, Abbate R, Gensini GF, Casini A, Sofi F (2017) Vegetarian, vegan diets and multiple health outcomes: a systematic review with meta-analysis of observational studies. Crit Rev Food Sci Nutr 57:3640-3649. https://doi.org/10.1080/10408398.2016.1138447

12. Viguiliouk E, Kendall CW, Kahleová H et al (2018) Effect of vegetarian dietary patterns on cardiometabolic risk factors in diabetes: a systematic review and meta-analysis of randomized controlled trials. Clin Nutr pii S0261-5614(18):30220-30226. https://doi.org/10.1016/j.clnu.2018.05.032

13. Turner-McGrievy G, Harris M (2014) Key elements of plant-based diets associated with reduced risk of metabolic syndrome. Curr Diab Rep 14:524. https://doi.org/10.1007/s11892-014-0524-y

14. Martínez-González MA, Sánchez-Tainta A, Corella D et al (2014) A provegetarian food pattern and reduction in total mortality in the Prevención con Dieta Mediterránea (PREDIMED) study. Am J Clin Nutr 100(Suppl 1):320S-S328. https://doi.org/10.3945/ajen.113.071431

15. Satija A, Bhupathiraju SN, Rimm EB et al (2016) Plant-based dietary patterns and incidence of Type 2 diabetes in US Men and women: results from three prospective cohort studies. PLoS Med 13:e1002039. https://doi.org/10.1371/journal.pmed.1002039

16. Satija A, Bhupathiraju SN, Spiegelman D et al (2017) Healthful and unhealthful plant-based diets and the risk of coronary heart disease in U.S. Adults J Am Coll Cardiol 70:411-422. https://doi. org/10.1016/j.jacc.2017.05.047

17. Gómez-Donoso C, Martínez-González MÁ, Martínez JA et al (2019) A provegetarian food pattern emphasizing preference for healthy plant-derived foods reduces the risk of overweight/obesity in the SUN cohort. Nutrients 11. pii: E1553. https://doi.org/10. 3390/nu11071553

18. Martínez-González MA, Buil-Cosiales P, Corella D et al (2019) Cohort profile: design and methods of the PREDIMED-plus randomized trial. Int J Epidemiol 48:387-388o. https://doi.org/10. 1093/ije/dyy 225

19. Alberti KG, Eckel RH, Grundy SM et al (2009) Harmonizing the metabolic syndrome: a joint interim statement of the International Diabetes Federation Task Force on Epidemiology and Prevention; National Heart, Lung, and Blood Institute; American Heart Association; World Heart Federation; International. Circulation 120:1640 1645. https://doi.org/10.1161/CIRCULATIONAHA.109.192644

20. Willett W (1998) Nutritional epidemiology. Oxford University Press, New York

21. Martin-Moreno JM, Boyle P, Gorgojo L et al (1993) Development and validation of a food frequency questionnaire in Spain. Int $\mathrm{J}$ Epidemiol 22:512-519. https://doi.org/10.1093/ije/22.3.512

22. Fernández-Ballart JD, Piñol JL, Zazpe I et al (2010) Relative validity of a semi-quantitative food-frequency questionnaire in an elderly Mediterranean population of Spain. Br J Nutr 103:18081816. https://doi.org/10.1017/S0007114509993837

23. Willett WC, Howe GR, Kushi LH (1997) Adjustment for total energy intake in epidemiologic studies. Am J Clin Nutr 65(4 Suppl):1220S-1228S. https://doi.org/10.1093/ajcn/65.4.1220S (discussion 1229S-1231S)

24. Franks PW, Ekelund U, Brage S, Wong MY, Wareham NJ (2004) Does the association of habitual physical activity with the metabolic syndrome differ by level of cardiorespiratory fitness? Diabetes Care 27:1187-1193. https://doi.org/10.2337/diacare.27.5.1187

25. Molina L, Sarmiento M, Peñafiel J et al (2017) Validation of the regicor short physical activity questionnaire for the adult population. PLoS One 12:e0168148. https://doi.org/10.1371/journ al.pone. 0168148

26. Schröder H, Fitó M, Estruch R et al (2011) A short screener is valid for assessing Mediterranean diet adherence among older Spanish men and women. J Nutr 141:1140-1145. https://doi.org/ 10.3945/jn.110.135566

27. McKean JW (2004) Robust analysis of linear models. Statist Sci 19:562-570. https://doi.org/10.1214/088342304000000549

28. Kim H, Lee K, Rebholz CM, Kim J (2020) Plant-based diets and incident metabolic syndrome: results from a South Korean prospective cohort study. PLoS Med 17:e1003371. https://doi.org/10. 1371/journal.pmed.1003371

29. Orlich MJ, Fraser GE (2014) Vegetarian diets in the Adventist Health Study 2: a review of initial published findings. Am J Clin Nutr 100(Suppl 1):353S-S358. https://doi.org/10.3945/ajcn.113.071233

30. Satija A, Malik V, Rimm EB, Sacks F, Willett W, Hu FB (2019) Changes in intake of plant-based diets and weight change: results from 3 prospective cohort studies. Am J Clin Nutr 110:574-582. https://doi.org/10.1093/ajcn/nqz049

31. Kim H, Caulfield LE, Garcia-Larsen V, Steffen LM, Coresh J, Rebholz CM (2019) Plant-based diets are associated with a lower risk of incident cardiovascular disease, cardiovascular disease mortality, and all-cause mortality in a general population of middle-aged adults. J Am Heart Assoc 8:e012865. https://doi.org/10. 1161/JAHA.119.012865

32. Martínez-González MA, Fernandez-Lazaro CI, Toledo E et al (2020) Carbohydrate quality changes and concurrent changes in cardiovascular risk factors: a longitudinal analysis in the PREDIMED-Plus randomized trial. Am J Clin Nutr 111:291-306. https://doi.org/10.1093/ajcn/nqz298

33. Najjar RS, Feresin RG (2019) Plant-based diets in the reduction of body fat: physiological effects and biochemical insights. Nutrients 11:2712. https://doi.org/10.3390/nu11112712

34. Rivellese AA, Giacco R, Costabile G (2012) Dietary carbohydrates for diabetics. Curr Atheroscler Rep 14:563-569. https:// doi.org/10.1007/s11883-012-0278-4

35. Chambers ES, Preston T, Frost G, Morrison DJ (2018) Role of gut microbiota-generated short-chain fatty acids in metabolic and cardiovascular health. Curr Nutr Rep 7:198-206. https://doi.org/ 10.1007/s 13668-018-0248-8

36. Yokoyama Y, Levin SM, Barnard ND (2017) Association between plant-based diets and plasma lipids: a systematic review and metaanalysis. Nutr Rev 75:683-698. https://doi.org/10.1093/nutrit/nux030

37. Ros E (2009) Nuts and novel biomarkers of cardiovascular disease. Am J Clin Nutr 89:1649S-S1656. https://doi.org/10.3945/ ajcn.2009.26736R

38. Ma L, Hu L, Feng X, Wang S (2018) Nitrate and nitrite in health and disease. Aging Dis. 9:938-945. https://doi.org/10.14336/AD. 2017.1207

39. Monteiro CA (2009) Nutrition and health. The issue is not food, nor nutrients, so much as processing. Public Health Nutr 12:729731. https://doi.org/10.1017/S1368980009005291

40. Srour B, Fezeu LK, Kesse-Guyot E et al (2019) Ultra-processed food intake and risk of cardiovascular disease: prospective cohort study (NutriNet-Santé). BMJ 365:11451. https://doi.org/10.1136/ bmj.11451

41. Silva Meneguelli T, Viana Hinkelmann J, Hermsdorff HHM, Zulet MÁ, Martínez JA, Bressan J (2020) Food consumption by degree of processing and cardiometabolic risk: a systematic review. Int J Food Sci Nutr 71:678-692. https://doi.org/10.1080/09637486. 2020.1725961

42. Fresán U, Martínez-González MA, Sabaté J, Bes-Rastrollo M (2019) Global sustainability (health, environment and monetary costs) of three dietary patterns: results from a Spanish cohort (the SUN project). BMJ Open 9:e021541. https://doi.org/10.1136/ bmjopen-2018-021541 


\title{
Authors and Affiliations
}

\author{
Alejandro Oncina-Cánovas ${ }^{1,2,3}$. Jesús Vioque 1,2,3,33 ( Sandra González-Palacios ${ }^{1,2,3}$. \\ Miguel Ángel Martínez-González ${ }^{4,5,6}$. Jordi Salas-Salvadóto,7,8,9 . Dolores Corella ${ }^{4,10}$. Dolores Zomeño ${ }^{4,11}$. \\ J. Alfredo Martínez $z^{4,12,13}$ • Ángel M. Alonso-Gómez ${ }^{4,14}$. Julia Wärnberg ${ }^{4,15}$ • Dora Romaguera ${ }^{4,16}$. \\ José López-Miranda ${ }^{4,17}$. Ramon Estruch ${ }^{4,18} \cdot$ Rosa M. Bernal-Lopez ${ }^{4,19}$. José Lapetra ${ }^{4,20}$. J. Luís Serra-Majem ${ }^{4,21}$. \\ Aurora Bueno-Cavanillas ${ }^{1,22}$. Josep A. Tur ${ }^{4,23} \cdot$ Vicente Martín-Sánchez $^{10,24} \cdot$ Xavier Pintót $^{4,25}$. \\ Miguel Delgado-Rodríguez ${ }^{10,26}$. Pilar Matía-Martín ${ }^{27}$. Josep Vidal ${ }^{28,29} \cdot$ Clotilde Vázquez $^{4,30} \cdot$ Lidia Daimiel $^{31}$. \\ Emili Ros ${ }^{4,32} \cdot$ Estefanía Toledo ${ }^{4,5} \cdot$ Nancy Babio $^{4,7,8,9}$. Jose V. Sorli ${ }^{4,10} \cdot$ Helmut Schröder $^{1,11} \cdot$ María Angeles Zulet $^{4,12}$. \\ Carolina Sorto-Sánchez ${ }^{4,14} \cdot$ Francisco Javier Barón-López ${ }^{4,15} \cdot$ Laura Compañ-Gabucio $^{1,2,3} \cdot$ Marga Morey $^{4,16}$. \\ Antonio García-Ríos ${ }^{4,17}$. Rosa Casas ${ }^{4,18}$. Ana María Gómez-Pérez ${ }^{4,19}$. José Manuel Santos-Lozano ${ }^{4,20}$. \\ Zenaida Vázquez-Ruiz ${ }^{4,5}$. Stephanie K. Nishi ${ }^{4,7,8,9} \cdot$ Eva M. Asensio ${ }^{4,10}$. Núria Soldevila ${ }^{1,11}$ • Itziar Abete ${ }^{4,12}$. \\ Leire Goicolea-Güemez ${ }^{4,14}$. Pilar Buil-Cosiales ${ }^{4,5}$. Jesús F. García-Gavilán ${ }^{4,7,8,9}$. Erik Canals ${ }^{1,11}$. \\ Laura Torres-Collado $^{1,2,3} \cdot$ Manuela García-de-la-Hera ${ }^{1,2,3}$
}

1 CIBER de Epidemiología y Salud Pública (CIBERESP), Instituto de Salud Carlos III, Madrid, Spain

2 Instituto de Investigación Sanitaria y Biomédica de Alicante, Universidad Miguel Hernández (ISABIAL-UMH), Alicante, Spain

3 Nutritional Epidemiology Unit, University Miguel Hernandez, Alicante, Spain

4 Centro de Investigación Biomédica en Red Fisiopatología de La Obesidad y La Nutrición (CIBEROBN), Institute of Health Carlos III, Madrid, Spain

5 Department of Preventive Medicine and Public Health, IDISNA, University of Navarra, Pamplona, Spain

6 Department of Nutrition, Harvard T.H. Chan School of Public Health, Boston, MA, USA

7 Departament de Bioquímica I Biotecnologia, Universitat Rovira I Virgili, Unitat de Nutrició, Reus, Spain

8 Nutrition Unit, University Hospital of Sant Joan de Reus, Reus, Spain

9 Institut D’Investigació Sanitària Pere Virgili (IISPV), Reus, Spain

10 Department of Preventive Medicine, University of Valencia, Valencia, Spain

11 Unit of Cardiovascular Risk and Nutrition, Institut Hospital del Mar de Investigaciones Médicas Municipal D’Investigació Médica (IMIM), Barcelona, Spain

12 Department of Nutrition, Food Sciences, and Physiology, University of Navarra, Pamplona, Spain

13 Precision Nutrition Program, IMDEA Food, CEI UAM + CSIC, Madrid, Spain

14 Bioaraba Health Research Institute, Cardiovascular, Respiratory and Metabolic Area, Osakidetza Basque Health Service, Araba University Hospital, University of the Basque Country UPV/EHU, Vitoria-Gasteiz, Spain

15 EpiPHAAN Research Group, School of Health Sciences, Instituto de Investigación Biomédica de Málaga (IBIMA), University of Málaga, 29010 Málaga, Spain
16 Health Research Institute of the Balearic Islands (IdISBa), Palma de Mallorca, Spain

17 Department of Internal Medicine, Maimonides Biomedical Research Institute of Cordoba (IMIBIC), Reina Sofia University Hospital, University of Cordoba, Cordoba, Spain

18 Department of Internal Medicine, Institut D'Investigacions Biomèdiques August Pi Sunyer (IDIBAPS), Hospital Clinic, University of Barcelona, Barcelona, Spain

19 Department of Endocrinology, Instituto de Investigación Biomédica de Málaga (IBIMA), Virgen de La Victoria Hospital, University of Málaga, Málaga, Spain

20 Department of Family Medicine, Research Unit, Distrito Sanitario Atención Primaria Sevilla, Sevilla, Spain

21 Research Institute of Biomedical and Health Sciences (IUIBS), University of Las Palmas de Gran Canaria and Centro Hospitalario Universitario Insular Materno Infantil (CHUIMI), Canarian Health Service, Las Palmas de Gran Canaria, Spain

22 Department of Preventive Medicine and Public Health, University of Granada, Granada, Spain

23 Research Group on Community Nutrition and Oxidative Stress, University of Balearic Islands, Palma de Mallorca, Spain

24 Institute of Biomedicine (IBIOMED), University of León, León, Spain

25 Lipids and Vascular Risk Unit, Internal Medicine, Hospital Universitario de Bellvitge, Hospitalet de Llobregat, Barcelona, Spain

26 Division of Preventive Medicine, Faculty of Medicine, University of Jaén, Jaén, Spain

27 Department of Endocrinology and Nutrition, Instituto de Investigación Sanitaria Hospital Clínico San Carlos (IdISSC), Madrid, Spain

28 CIBER Diabetes y Enfermedades Metabólicas (CIBERDEM), Instituto de Salud Carlos III (ISCIII), Madrid, Spain 
29 Department of Endocrinology, Institut D'Investigacions Biomédiques August Pi Sunyer (IDIBAPS), Hospital Clinic, University of Barcelona, Barcelona, Spain

30 Department of Endocrinology and Nutrition, Hospital Fundación Jimenez Díaz, Instituto de Investigaciones Biomédicas IISFJD, University Autonoma, Madrid, Spain

31 Nutritional Control of the Epigenome Group, IMDEA Food, CEI UAM + CSIC, Madrid, Spain
32 Lipid Clinic, Department of Endocrinology and Nutrition, Institut D'Investigacions Biomèdiques August Pi Sunyer (IDIBAPS), Hospital Clínic, Barcelona, Spain

33 Dpto. Salud Pública, Facultad de Medicina, $\mathrm{H}^{\mathrm{a}}$ de La Ciencia y Ginecología, Avda. Ramón y Cajal s/n, Sant Joan d'Alacant, 03550 Alicante, Spain 